\title{
Confined and interface phonons in combined cylindrical nanoheterosystem
}

\author{
O.M.Makhanets, O.M.Voitsekhivska, A.M.Gryschyk \\ Fedkovych Chernivtsi National University, 2, Kotsyubinskoho Str., Chernivtsi, 58012, Ukraine*
}

Received March 31, 2006, in final form June 2, 2006

The spectra of all types of phonons existing in a complicated combined nanoheterosystem consisting of three cylindrical quantum dots embedded into the cylindrical quantum wire placed into vacuum are studied within the dielectric continuum model. It is shown that there are confined optical (LO) and interface phonons of two types: top surface optical (TSO) and side surface optical (SSO) modes of vibration in such a nanosystem. The dependences of phonon energies on the quasiwave numbers and geometrical parameters of quantum dots are investigated and analysed.

Key words: nanoheterosystem, phonon, energy spectrum

PACS: $68.65 . H b, 68.65 . \mathrm{La}, 74.25 . \mathrm{Kc}$

\section{Introduction}

Recently, the complicated combined nanoheterosystems containing different spatial combinations of quantum dots (QD), wires (QW) and wells have been intensively researched. Such systems have already been created experimentally and have good prospects of being utilized in the devices of physical, biomedical and optical electronics [1]. For example, in the systems containing two or more QD's an electron practically without any loss of energy can be localized in different quantum dots due to the anticrossing effect. Such systems create a single quabit and can be used as an elementary base of modern quantum computer [2-4].

The theoretical investigations of combined nanoheterosystems are only at the very start. Their importance is obvious but there are a priori some difficulties arising due to the complicated boundary conditions for the wave functions of quasiparticles (electrons, holes, excitons) and polarization potentials of free vibrations (phonons). In paper [5] the energy spectrum and life times of quasiparticles in the open QD embedded into the cylindrical QW have been studied within the framework of the effective mass approximation using the scattering matrix method. It was shown that the energy loss of the quasiparticles inside the QD arises due to their tunneling through the potential barrier into the external medium. It is clear that the change of the quantum state of the quasiparticle (electron, hole, exciton) is accompanied by the processes of creation and annihilation of phonons. Consequently, there is an additional channel of energy relaxation and finally it causes the change in the quasiparticle energy spectrum.

This paper presents theoretical investigations of the phonon spectrum in combined nanoheterosystems consisting of three QD's embedded into the cylindrical semiconductor QW placed into the medium. The study is performed within the dielectric continuum model widely applied in other papers $[6,7]$ and the results of which are in good agreement with the experimental data.

\section{Theory}

The spectra of all types of phonons existing in the complicated combined nanoheterosystem consisting of three cylindrical quantum dots (CdS "1", HgS "0", CdS "1") embedded into the

\footnotetext{
*E-mail: theorphys@chnu.cv.ua
} 


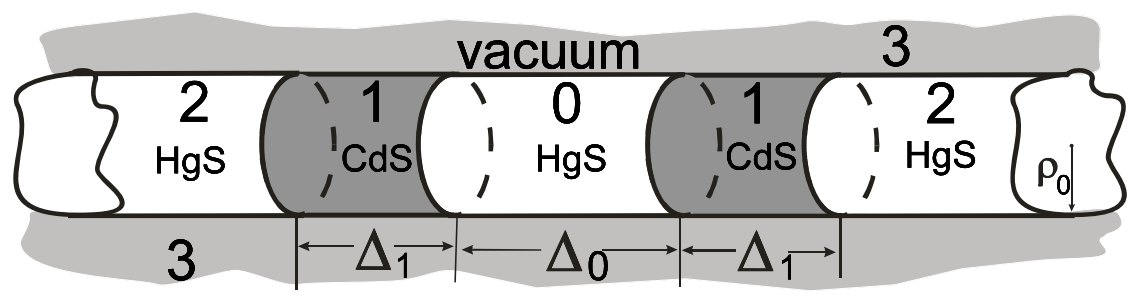

Figure 1. Geometrical scheme of combined cylindrical nanosystem.

cylindrical quantum wire (HgS "2") placed into the external medium (vacuum "3", figure 1) are under study. The radii of all QD's and QW are assumed to be equal $\left(\rho_{0}\right)$, the height of the internal $\mathrm{QD}$ is $\Delta_{0}$ and that of the external is $\Delta_{1}$, the dielectric constant

$$
\varepsilon_{i}(\omega)=\varepsilon_{i \infty} \frac{\omega^{2}-\omega_{\mathrm{L} i}^{2}}{\omega^{2}-\omega_{\mathrm{T} i}^{2}}, \quad i=0,1,2,
$$

where $\varepsilon_{i \infty}$ - is high frequency dielectric constant of the $i^{\text {th }}$ part of nanosystem, $\omega_{\mathrm{L} i}$ and $\omega_{\mathrm{T} i}-$ are the frequencies of longitudinal and transversal optical phonons of its bulk analogue and $\varepsilon_{3}=1$. As it follows from the dielectric continuum model the phonon spectrum for such a system is obtained by combining the electrostatic equations and getting the equation [6]

$$
\varepsilon_{i}(\omega) \nabla^{2} \Phi(\vec{r})=0,
$$

where $\Phi(\vec{r})$ is the potential of phonon polarization field. It is obvious that there are two possible solutions to this equation defining the spectra of confined and interface phonons which are further observed separately.

\section{Confined phonons}

It is clear that at the condition

$$
\varepsilon_{i}(\omega)=0, \quad \nabla^{2} \Phi(\vec{r}) \neq 0
$$

and taking into account equation (1) one can obtain the spectrum of confined optical (LO) phonons

$$
\Omega_{\mathrm{L} i}=\hbar \omega_{\mathrm{L} i}, \quad i=0,1,2,
$$

the energies of which are equal to the energies of the longitudinal phonons of the corresponding bulk analogues of the nanosystem parts.

According to the symmetry of the system the polarization potential of the LO phonons can be chosen as

$$
\Phi_{m}(\vec{r})=J_{m}(k \rho) f(z) \mathrm{e}^{\mathrm{i} m \varphi},
$$

where

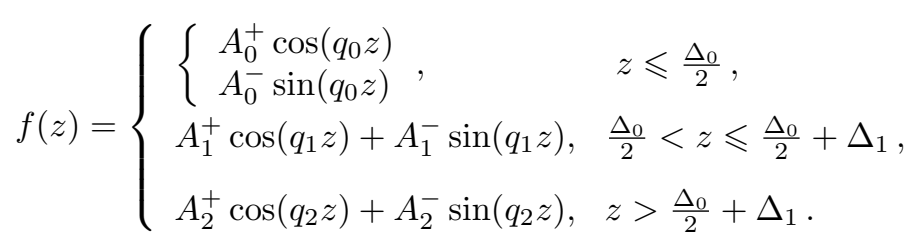

Here $\mathrm{m}$ is magnetic quantum number, $q_{i}$ and $k=X_{n}^{m} \rho_{0}^{-1},-$ are the quasiwave numbers, $X_{n}^{m}$ is n-th root of m-th order Bessel function and $A_{i}^{ \pm}$are unknown coefficients determined by the boundary conditions of electrostatic: the continuity of the polarization potential $\Phi_{m}(\vec{r})$ and normal terms of electric displacement $\vec{D}$ at the media interfaces. 


\section{Interface phonons}

The spectra of interface phonons due to the equation (2) are obtained from the Laplace's equation

$$
\Delta \Phi(\vec{r})=0
$$

the solution of which in the cylindrical coordinates $(\rho, \varphi, \mathrm{z})$ can be generally written as

$$
\Phi(\vec{r})=\varphi(\rho) F(z) \mathrm{e}^{\mathrm{i} m \varphi} .
$$

It is clear that the solutions for the four planes are quite different from that of the solutions at the side walls. One knows [6] that depending on the boundary conditions for the $\varphi(\rho)$ and $F(z)$ functions there are two types of interface phonon modes: top surface optical (TSO) modes, whose amplitude decreases away from the four planes; and side surface optical (SSO) modes, whose amplitude decreases away from the side walls.

\section{Spectrum of TSO phonons}

For the TSO modes the function has to describe the non-decaying potential in the plane perpendicular to the $\mathrm{OZ}$ axis and the decaying one along this axis. Thus, they are chosen in the form

$$
\begin{gathered}
\varphi(\rho)= \begin{cases}J_{m}(q \rho), & \rho \leqslant \rho_{0} \\
N_{m}(q \rho), & \rho>\rho_{0}\end{cases} \\
F(z)= \begin{cases} \begin{cases}B_{0}^{+} \operatorname{ch}(q z) \\
B_{0}^{-} \operatorname{sh}(q z),\end{cases} & z \leqslant \frac{\Delta_{0}}{2} \\
B_{1}^{+} \operatorname{ch}(q z)+B_{1}^{-} \operatorname{sh}(q z), & \frac{\Delta_{0}}{2}<z \leqslant \frac{\Delta_{0}}{2}+\Delta_{1} \\
B_{2} e^{-q z}, & z>\frac{\Delta_{0}}{2}+\Delta_{1}\end{cases}
\end{gathered}
$$

Again, from the boundary conditions for polarization potential $F(z)$ and normal terms of electric displacement $\vec{D}$ at $z=\frac{\Delta_{0}}{2}$ and $z=\frac{\Delta_{0}}{2} \Delta_{1}$ it is obtained $B_{i}^{+}=0, B_{i}^{-} \neq 0$ (antisymmetric TSO modes) or $B_{i}^{-}=0, B_{i}^{+} \neq 0$ (symmetric TSO modes). As a result we get a system of four equations for determining the frequencies of symmetric $\left(\omega_{+}\right)$and antisymmetric $\left(\omega_{-}\right)$TSO phonons. The detailed analytical solution of the similar system has been performed in paper [8] where the equation was obtained for defining the TSO phonon spectra but there were no numeric calculations for real nanosystems. We are going to further analyse the results of computer calculations performed for the system under research.

\section{Spectrum of SSO phonons}

It is clear that for the SSO modes the $F(z)$ function has to describe the non-decaying potential along the $\mathrm{OZ}$ axis and the decaying $\varphi(\rho)$ in the plane perpendicular to this axis. Taking into account the symmetry, the polarization potential is expressed as

$$
\Phi(\vec{r})=\left\{\begin{array}{lc}
D_{i}^{ \pm} I_{m}(k \rho) C_{s}^{ \pm}(k z) \mathrm{e}^{\mathrm{i} m \varphi}, & \rho \leqslant \rho_{0}, \\
C_{i}^{ \pm} K_{m}(k \rho) C_{s}^{ \pm}(k z) \mathrm{e}^{\mathrm{i} m \varphi}, & \rho>\rho_{0}
\end{array}\right.
$$

herein

$$
C_{s}^{ \pm}(k z)=\left\{\begin{array}{l}
\cos (k z), \\
\sin (k z) .
\end{array}\right.
$$

The unknown coefficients are found during the second quantization of the phonon field, $I_{m}(k \rho)$ and $K_{m}(k \rho)$ - are the m-th order modified Bessel functions of the first and the second kind. The frequencies of SSO phonons are determined by the boundary conditions for polarization potential $\Phi(\vec{r})$ and normal terms of electric displacement at $\rho=\rho_{0}$.

$$
\left\{\begin{array}{l}
\left.D_{i}^{ \pm} I_{m}(k \rho)\right|_{\rho=\rho_{0}} C_{s}^{ \pm}(k z) \mathrm{e}^{\mathrm{i} m \varphi}=\left.C_{3}^{ \pm} K_{m}(k \rho)\right|_{\rho=\rho_{0}} C_{s}^{ \pm}(k z) \mathrm{e}^{\mathrm{i} i \varphi}, \\
\left.\varepsilon_{i} D_{i}^{ \pm} I_{m}^{\prime}(k \rho)\right|_{\rho=\rho_{0}} C_{s}^{ \pm}(k z) \mathrm{e}^{\mathrm{i} m \varphi}=\left.\varepsilon_{3} C_{3}^{ \pm} K_{m}^{\prime}(k \rho)\right|_{\rho=\rho_{0}} C_{s}^{ \pm}(k z) \mathrm{e}^{\mathrm{i} m \varphi},
\end{array}\right.
$$


here $\varepsilon_{3}=1$ since the external medium is vacuum. Taking the ratio of these equations one can write

$$
\varepsilon_{i} \frac{I_{m}^{\prime}\left(k \rho_{0}\right)}{I_{m}\left(k \rho_{0}\right)}=\frac{K_{m}^{\prime}\left(k \rho_{0}\right)}{K_{m}\left(k \rho_{0}\right)} .
$$

Solving the latter and using equation (1) a dispersional equation is obtained for the frequencies of SSO modes in i-th part of nanosystem

$$
\begin{aligned}
\omega_{i}\left(k \rho_{0}\right) & =\frac{\sqrt{\left(P\left(k \rho_{0}\right)-\varepsilon_{i \infty}\right)\left(\omega_{\mathrm{T} i}^{2} P\left(k \rho_{0}\right)-\omega_{\mathrm{Li}}^{2} \varepsilon_{i \infty}\right)}}{P\left(k \rho_{0}\right)-\varepsilon_{i \infty}}, \\
P\left(k \rho_{0}\right) & =\frac{I_{m}\left(k \rho_{0}\right)}{K_{m}\left(k \rho_{0}\right)} \frac{m K_{m}\left(k \rho_{0}\right)-k \rho_{0} K_{m+1}\left(k \rho_{0}\right)}{m I_{m}\left(k \rho_{0}\right)+k \rho_{0} I_{m+1}\left(k \rho_{0}\right)} .
\end{aligned}
$$

The equations (15),(16) prove that the energies of the side surface phonons create the bands over the magnetic quantum number $m$.

\section{Analysis of the results}

The results of the computer calculations performed with the material parameters of $\beta$-HgS and $\beta$-CdS [9] of the interface phonon energies are shown in figures 2-4. All of them prove that the spectra of interface phonons depend on the geometric parameters of nanosystem and the type of vibrations ( $\mathrm{SSO}$ or TSO) but the energies of all these phonon modes are always located between the energies of LO and TO phonons of the respective bulk crystals $\left(\Omega_{\mathrm{LCdS}}, \Omega_{\mathrm{T} C d S}\right.$, and $\Omega_{\mathrm{LHgS}}$, $\Omega_{\mathrm{T} H g S}$ shown in the figures by dashed lines).
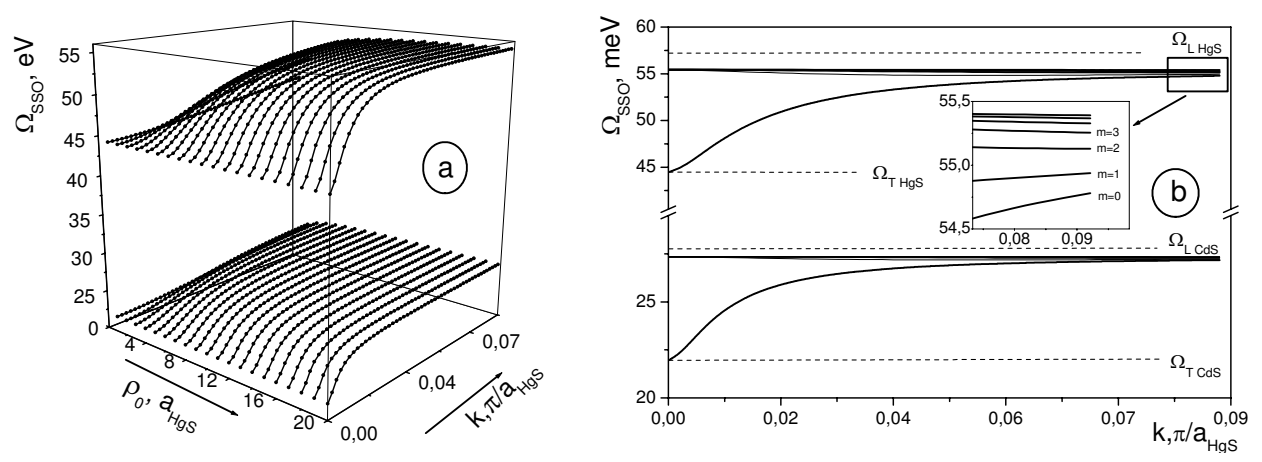

Figure 2. Evolution of SSO phonon energy on the quasiwave number and radius of $\mathrm{HgS}$ QD.

(a): for $\mathrm{m}=0$ and (b): on the quasiwave number for $\mathrm{m}=0,1,2, \ldots$ at $\rho_{0}=10 a_{\mathrm{HgS}}$.

Figure 2a presents the dependence of SSO phonon energies on the radius of QW $\rho_{0}$ and quasiwave number $\mathrm{k}$. One can see that there are two modes of SSO phonons arising due to the two sets of interfaces $\mathrm{HgS} /$ vacuum and $\mathrm{CdS}$ /vacuum. It is clear that the dispersion over the quasiwave number is rather weak. There are the sets of modes with different magnetic quantum numbers (figure $2 \mathrm{~b}$ ) and the energies of SSO phonons which are almost the same as for the energy with $\mathrm{m}=1$.

Figures 3a,b,c,d shows the evolution of TSO phonon energy spectra as a function of the quasiwave number $q$ for different thicknesses $\left(\Delta_{0}\right)$ of QD $\mathrm{HgS}$ at a fixed thickness of QD CdS $\left(\Delta_{1}=5 a_{\mathrm{CdS}}\right)$. When the QD HgS is absent $\Delta_{0}=0$ (figure 3a) there are four modes of TSO vibrations: two modes with positive (symmetric $\omega_{+}$) and two modes with negative (antisymmetric $\omega_{-}$) dispersion. Their existence is caused by the presence of two interfaces between QD CdS and QW $\mathrm{HgS}$. The arising of $\mathrm{HgS}$ QD $\left(\Delta_{0}=5 a_{\mathrm{HgS}}\right.$, figure $3 \mathrm{c} ; \Delta_{0}=10 a_{\mathrm{HgS}}$, figure $\left.3 \mathrm{~d}\right)$ and the increase of its thickness brings about the appearance of four new modes (caused by two additional interfaces) 

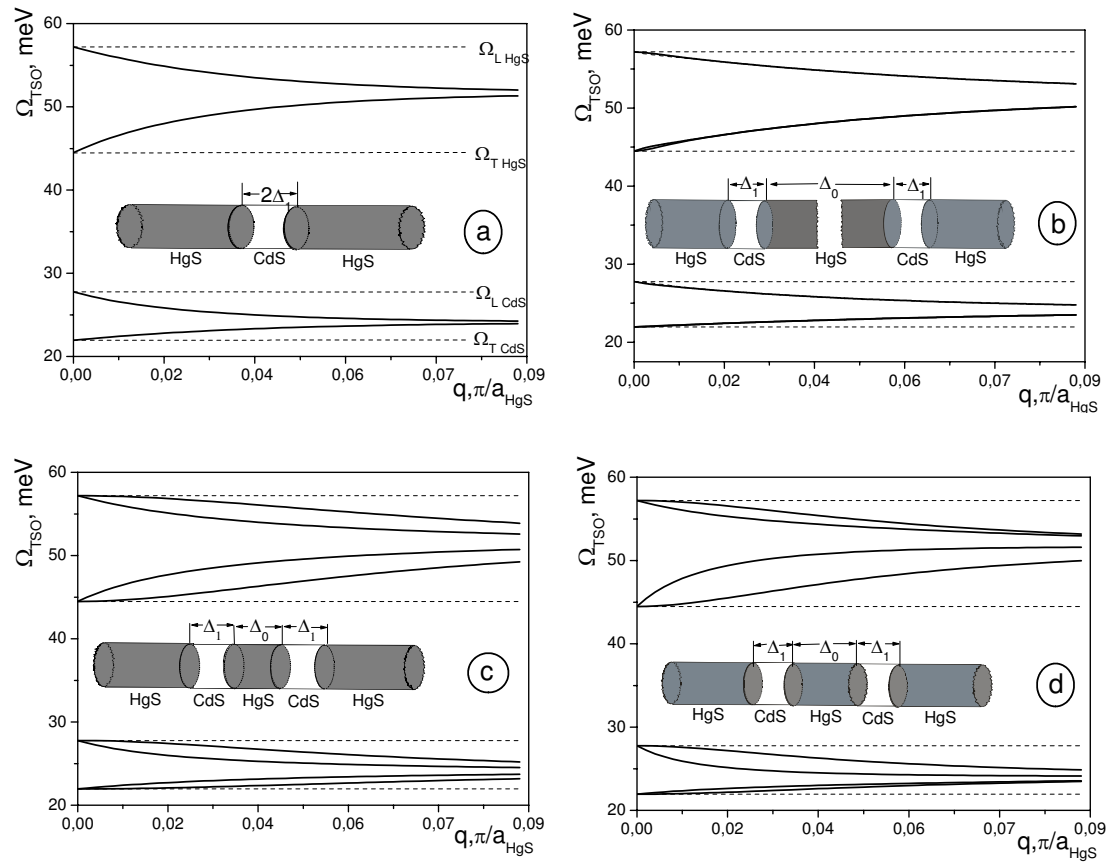

Figure 3. Dependence of TSO phonon energy on the quasiwave number at a fixed thickness of CdS QD $\left(\Delta_{1}=5 a_{\mathrm{CdS}}\right)$ for different thicknesses of HgS QD. (a): $\Delta_{0}=0 a_{\mathrm{HgS}}$, (b): $\Delta_{0}=100 a_{\mathrm{HgS}}$, c: $\Delta_{0}=5 a_{\mathrm{HgS}}, \mathrm{d}: \Delta_{0}=10 a_{\mathrm{HgS}}$.
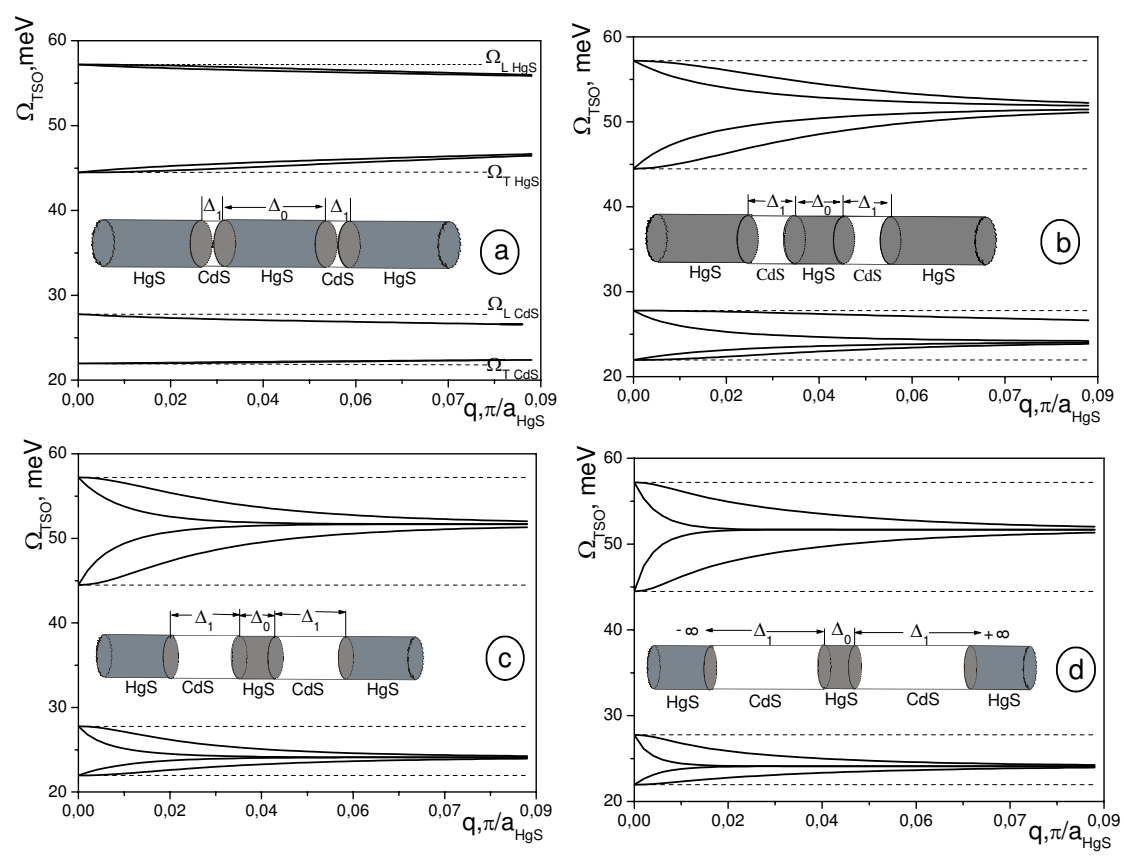

Figure 4. Dependence of TSO phonon energy on the quasiwave number at a fixed thickness of $\operatorname{HgS~QD~}\left(\Delta_{0}=10 a_{\mathrm{HgS}}\right)$ for different thicknesses of CdS QD. (a): $\Delta_{1}=1 a_{\mathrm{CdS}}$, (b): $\Delta_{1}=10 a_{\mathrm{CdS}}$, (c): $\Delta_{0}=20 a_{\mathrm{CdS}}, \mathrm{d}: \Delta_{0}=40 a_{\mathrm{CdS}}$. 
with different dispersion. At $\Delta_{0} \rightarrow \infty$ (figure $3 \mathrm{~b}$ ) eight modes of TSO vibrations again degenerate into four. This is clear because the case of $\Delta_{0} \rightarrow \infty$ with the thickness $\Delta_{1}$ of QD CdS (figure 3b) is almost equivalent to the case of $\Delta_{0}=0$ (figure 3a) but with the thickness of $2 \Delta_{1}$ of CdS QD.

The evolution of TSO phonon spectra as function of quasiwave number with the increase of QD CdS thickness at a fixed thickness of QD HgS $\left(\Delta_{0}=10 a_{\mathrm{HgS}}\right)$ is shown in figures 4a,b,c,d. It is clear that there are also eight modes of TSO vibrations just like in the previous case. At the increase of $\Delta_{1}$ four of them are degenerated into two (figure $4 \mathrm{~d}$ ), because the energies of the symmetric and antisymmetric vibrations the potential of which is localized at the plus or minus infinity coincide.

The obtained information about the frequencies of all types of phonons existing in the combined cylindrical nanoheterosystem and their dispersion laws would be further used for the investigation of electron-, hole- and exciton-phonon interaction.

\title{
References
}

1. Siegel R.W. Assembling Materials From Nanoscale Building Blocks. Proc. E-MRS, 25, 2004.

2. Hayashi T., Fujisawa T., Cheong H.D., Jeong Y.H., Hirayama Y., Phys. Rev. Lett., 2003, 91, 226804.

3. Fujisawa T., Hayashi T., Cheong H.D., Jeong Y.H., Hirayama Y., Physica E (Amsterdam), 2004, 21, 1046.

4. Vorojtsov S., Mucciolo E.R., Baranger H.U., Phys. Rev. B, 2005, 71, 205322.

5. Tkach N.V., Makhanets A.M., FTT, 2005, 47, 550 (in Russian).

6. Wai-Sang Li, Chuan-Yu Chen, Physica B, 1997, 375.

7. Wang X.F., Lei X.L., Phys. Rev. B, 1994, 49, 4780.

8. Tkach N.V., Makhanets A.M., Zharkoy V.P., J. of Phys. Stud., 2005, 9, 163 (in Ukrainian).

9. Tkach N.V., Pronyshyn I.V., Makhanets A.M., UFJ, 1997, 42, 740 (in Ukrainian).

\section{Обмежені та інтерфейсні фонони в комбінованих циліндричних наносистемах}

\author{
О.М.Маханець, О.М.Войцехівська, А.М.Грищук \\ Чернівецький національний університет ім. Юрія Федьковича, вул. Коцюбинського 2, 58012, \\ Чернівці \\ Отримано 31 березня 2006 р., в остаточному вигляді - 2 червня 2006 р.
}

У моделі діелектричного континууму вивчаються спектри всіх типів фононів, що існують у складній комбінованій наногетеросистемі, яка складається з трьох циліндричних квантових точок, уміщених в циліндричний квантовий дріт, який знаходиться у вакуумі. Показано, що у такій наносистемі $€$ обмежені оптичні (LO) та інтерфейсні фонони двох типів: вершинні поверхневі оптичні (TSO) та бічні поверхневі оптичні (SSO) моди коливань. Досліджено залежність енергій фононів від хвильових чисел та геометричних параметрів квантових точок.

Ключові слова: наносистема, фонон, енергетичний спектр

PACS: $68.65 . H b, 68.65 . \mathrm{La}, 74.25 . \mathrm{KC}$ 